\title{
IMAGEM DA ENFERMEIRA E SEU PAPEL NA SOCIEDADE: PERCEPÇÃO DE ALUNOS DO PROGRAMA DE FORMAÇÃO INTERDISCIPLINAR SUPERIOR
}

\author{
Vanessa Weingartner Pierrotti ${ }^{1}$ \\ Edinêis de Brito Guirardello \\ Vanessa Pellegrino Toledo 2 \\ ${ }^{1}$ Graduanda da Faculdade de Enfermagem - Unicamp \\ ${ }^{2}$ Enfermeira Doutora. Professora Associada da Faculdade de Enfermagem - Unicamp
}

INTRODUÇÃO: Apesar de sua atuação indispensável no processo de cuidado à saúde, diversos estudos mostram que a imagem da enfermeira percebida pela sociedade é carregada de estereótipos e pouco reconhecida quanto ao seu papel. O fato da profissão ser majoritariamente composta por mulheres, o caráter manual atribuído ao cuidado e a hierarquia entre o médico e a enfermeira contribuem para a desvalorização da sua imagem. OBJETIVO: Compreender a percepção sobre a imagem da enfermeira e seu papel na sociedade pelos alunos do Programa de Formação Interdisciplinar Superior (ProFIS). MÉTODO: Estudo qualitativo apoiado pela fenomenografia, referencial que busca explorar a forma com que as pessoas vivenciam e compreendem um mesmo fenômeno. Os dados foram coletados em uma instituição pública de ensino do interior paulista. Após aprovação do Comitê de Ética em Pesquisa, sob parecer 끈 2.302.571, a coleta de dados foi iniciada em Outubro/2017 e finalizada em Janeiro/2018 com oito alunos do ProFIS por meio de entrevistas semiestruturadas compostas pelas seguintes questões: "Você ou alguém que conhece já foi cuidado por uma enfermeira? Conte-me como foi esta experiência" e "Qual a imagem que você tem da enfermeira?". RESULTADOS: Organizados em duas categorias descritivas: 1. Percepção da imagem da enfermeira e 2. Papel da enfermeira na sociedade e analisados pela releitura dos quatro padrões de conhecimento em enfermagem de Bárbara Carper: o padrão empírico, entendido como a ciência da Enfermagem; o estético, que é a arte da Enfermagem; o conhecimento pessoal, compreendido pelo estabelecimento de uma relação genuína com as pessoas e o ético, que é o componente moral. Na primeira categoria, os entrevistados associaram à enfermeira características positivas, como 
atenciosa, cuidadosa, paciente e dedicada à profissão. Ela é essencial nos serviços de saúde, responsabiliza-se por todos os cuidados e pode diagnosticar e acompanhar as necessidades do indivíduo. Deve saber lidar com a alta demanda de serviço e se atentar para não causar erros durante a assistência. Esses atributos denotam o padrão empírico, visto que há um conhecimento sistematizado no cuidado. Porém, Ihe atribuíram características negativas como braveza, maus tratos e desatenção que evidenciam o padrão ético, visto que há um compromisso moral da enfermeira com o paciente. Os entrevistados reconheceram que a área de atuação da enfermeira é predominantemente hospitalar, sendo responsável pela gestão da unidade. Tem como funções a administração de medicações e vacinas, os cuidados com higiene, alimentação e feridas. Além disso, apontaram o uso das redes sociais como ferramenta importante para promover a visibilidade da profissão. Já da segunda categoria, emergiu a percepção de que a enfermeira mantém-se presente nas 24 horas do dia e possui maior vivência com o paciente do que o médico, apesar deste ser mais prestigiado pela sociedade e ela ser vista como uma assistente de suas ações. Assim, no padrão estético, a enfermeira tem a capacidade de intra-habitar o outro por meio da empatia, visto como alguém que possui um olhar mais humano na assistência pelos entrevistados. CONSIDERAÇÕES FINAIS: O uso da fenomenografia propiciou atingir o objetivo do estudo. Ressalta-se a importância da realização de novas pesquisas que visem compreender a imagem da enfermeira pela sociedade a fim de promover sua visibilidade.

Palavras-chave: Enfermagem. Percepção social. Papel do profissional de enfermagem. 